\title{
Analysis on Rolling Damping of a Conventional Boat fitted with T-shaped Bilge Keels
}

\author{
Yam Ke San, Gordon Chiew Chin Howe , Vincent Lee Chieng Chen , and Sukanta Roy \\ Department of Mechanical Engineering, Curtin University Malaysia, CDT 250 Miri Sarawak Malaysia.
}

\begin{abstract}
This work presents a numerical study on the effect of T-shaped bilge keels on the roll damping of a conventional boat. A scaled boat model with the same dimensions as that of Irkal et al. [2] was fitted with two Tshaped bilge keels at the edges of the model. Computational Fluid Dynamics method was employed to simulate the roll decay motion of the boat. The motion of the boat is captured using a 6DOF model and the Overset grid approach. Comparison was performed on the damping characteristics of the conventional I-shaped and the T-shaped bilge keels. In addition, the impact of the aspect ratio of the keel bilges on the roll damping of the boat was evaluated. It was found that the bilge keel aspect ratio influences the damping coefficient non-linearly. Sufficiently large aspect ratio, i.e. an aspect ratio greater than 2 , is necessary in order to obtain an effective damping on the peak angle.
\end{abstract}

\section{Introduction}

Stability is the ability of a boat vessel to return to its original position due to the presences of centre of buoyancy and vertical centre of gravity. When the negative stability occurs, boat will capsize due to the unbalance forces acting at the vessels. Thus the heave, pitch and roll are important characteristics for determining the stability of ships [1]. For rolling, the use of bilge keels is the most common method for damping the rolling motion. In the past, theoretical study on bilge keels designs is difficult owning to the significant viscous and eddies effects from the hull on the roll damping. Experimental method is more common. However, the advancement of computational fluid dynamic (CFD) has enabled theoretical study to simulate the complex viscous flows around the hull which significantly enhances the accuracy of the prediction on the roll damping. Indeed, a recent study by Irkal et al. [2] on the decay rolling motion of a barge with bilge keels has shown that a good match between the numerical method prediction and their experimental result. A comparison study on the full numerical method of a boat with bilge keels against the traditional inviscid result [3] also have shown that the inviscid approach significantly under-predicted the damping at high wave frequency range.

The shape and width of the keel bilges has been known to affect the damping coefficient of a boat [4-12]. The more vortices a bilge keel can generate the higher roll damping it can achieve [5]. A comparison study on round and sharp bilge keels [6] shows that sharp bilge keel is able to generate stronger vortices at the tip of the bilge keels and therefore has a greater damping coefficient. Using complex shape [7] has also shown to be able to generate more vortices and increase the roll damping.

This paper addresses the use of T-shaped keel bilges on roll damping of a common barge. T-shaped is a slight extension of the common I-shaped bilge keel. However, the increase of the surface area is expected to be able to induce strong vortices that can enhance the roll damping. In order to evaluate the effectiveness of the Tshaped bilge keels, comparison against the I-shaped will also be performed.

\section{Methodology}

We consider the scaled boat model used by Irkal et al. [2] as the model of the investigation. The model has a two Tshaped keel bilges fitted at both of its lower edges and is partially immersed in a tank as shown in Fig. 1. The boat is locked at its centre of mass, and is initially resting at an inclination angle $\emptyset_{0}$ of $20^{\circ}$ at $t=0 \mathrm{~s}$, and is then released from rest so that it can rotate about its transverse axis, as displayed in Fig. 1. The dimensions of the boat are 300 $\mathrm{mm}$ in breadth (i.e. beam, $B$ ) and $200 \mathrm{~mm}$ in depth $(D)$ so that the beam to depth ratio $(B / D)$ is 1.5 . The width of the boat is $580 \mathrm{~mm}$ (into the paper). The length of the flume of the tank is 10 times the length of the boat, the height is $800 \mathrm{~mm}$ and the width is $600 \mathrm{~mm}$. The water in the tank is filled up to half the height of the tank, and the boat is allowed to immersed in the water such that the ratio of the depth of the water tank to the draft of the boat is 1.67. The total displacement of a water mass by the boat is $20.88 \mathrm{~kg}$. The boat is made out of Perspex sheet, and possesses a moment of inertia $I$ value of $0.2248 \mathrm{~kg} \cdot \mathrm{m}^{2}$.

The first objective is to measure the free decay rolling of boat that is fitted with T-shaped bilge keels and 

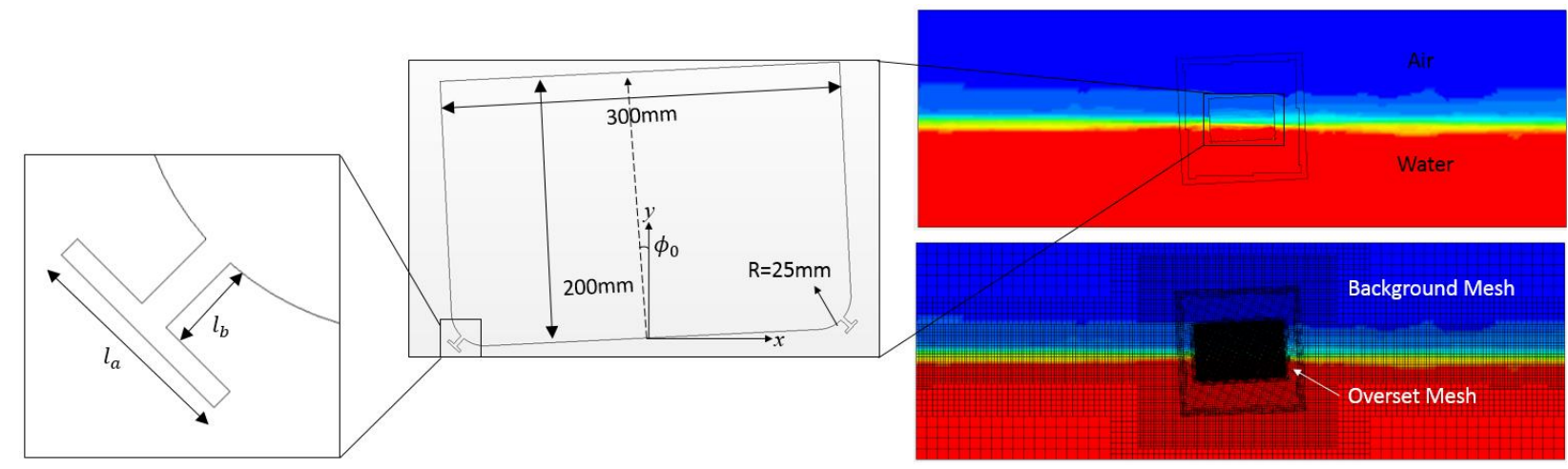

Figure 1 (left) length of the arm and body of a T-shaped bilge keel, (middle) the dimensions of a boat with T-shaped bilge keel, (top right) air and water domain, (bottom right) mesh distribution in the background and the Overset volume.

compare against that of conventional I-shaped bilge keels. The second objective is to investigate the effect of increases the aspect ratio of the T-shaped keel bilge, where the aspect ratio $A R$ of T-shaped is defined as the ratio of the length of the arms $l_{a}$ and the body $l_{b}$ as shown in Fig. 1.

Commercial Computational Fluid Dynamics (CFD) code StarCCM is employed to simulate the problem. Volume of Fluid (VOF) method is employed to simulate the air and water phases and the free surface interface. The motion of the boat is calculated using the Six Degree of Freedom (6DOF) model. However, in this case, the model is reduced to only $1 \mathrm{DOF}$ since the boat experiences the rotation only in one axis. The interaction between the motion of the boat and the hydrodynamic of the fluid is captured via force exchanges at the boundary boat. The fluid is assumed to be in laminar $\mathrm{c}$ ondition at atmospheric pressure. The surface boundary of the boat and the tank are assumed to be a wall (zero velocity at the surface). Because the front and the back of the boat are the same, we consider only half of the actual boat and tank in order to save computational cost. Symmetry boundary condition is then applied to the surface at the half of the domain.

Structured mesh is deployed in the computational domain for computing the fluid pressure and velocity. High mesh density is being applied in the vicinity of the water surface in order to capture a sharp transition of water free surface. Also high mesh density is applied at the boat boundary in order to capture the complex flows surrounding the bilge keels and to increase the accuracy of the force interaction calculation. A separate domain of structured mesh that overlaps with the background mesh (called the Overset mesh) is created for the boat to accommodate the relative motion of the boat. The coupling between the two meshes is performed via grid to grid connectivity model developed by StarCCM.

The governing equations are solved using Finite Volume Method. Second-order accurate discretization schemes are selected to achieve accurate solutions. The linear second-order upwind scheme was selected to discretize the spatial advection terms. First order Euler implicit scheme with a time step of $0.05 \mathrm{~s}$ was selected to numerically advance the time of the solution. The conservation of mass and momentum are enforced through segregated solver where the pressure, velocity and the phase volume fraction equations are solved sequentially and iteratively until the criterion on the minimum residue (a value of 1e-4) is met for each equation. In addition, a sharpening factor of 1 is applied to the VOF model to enhance the water-air interface.

A total 7 simulations were performed. One is on I-shaped bilge keel, and the remaining are on T-shaped bilge keels with the aspect ratio $A R$ ranges from 0.5 to 3 .

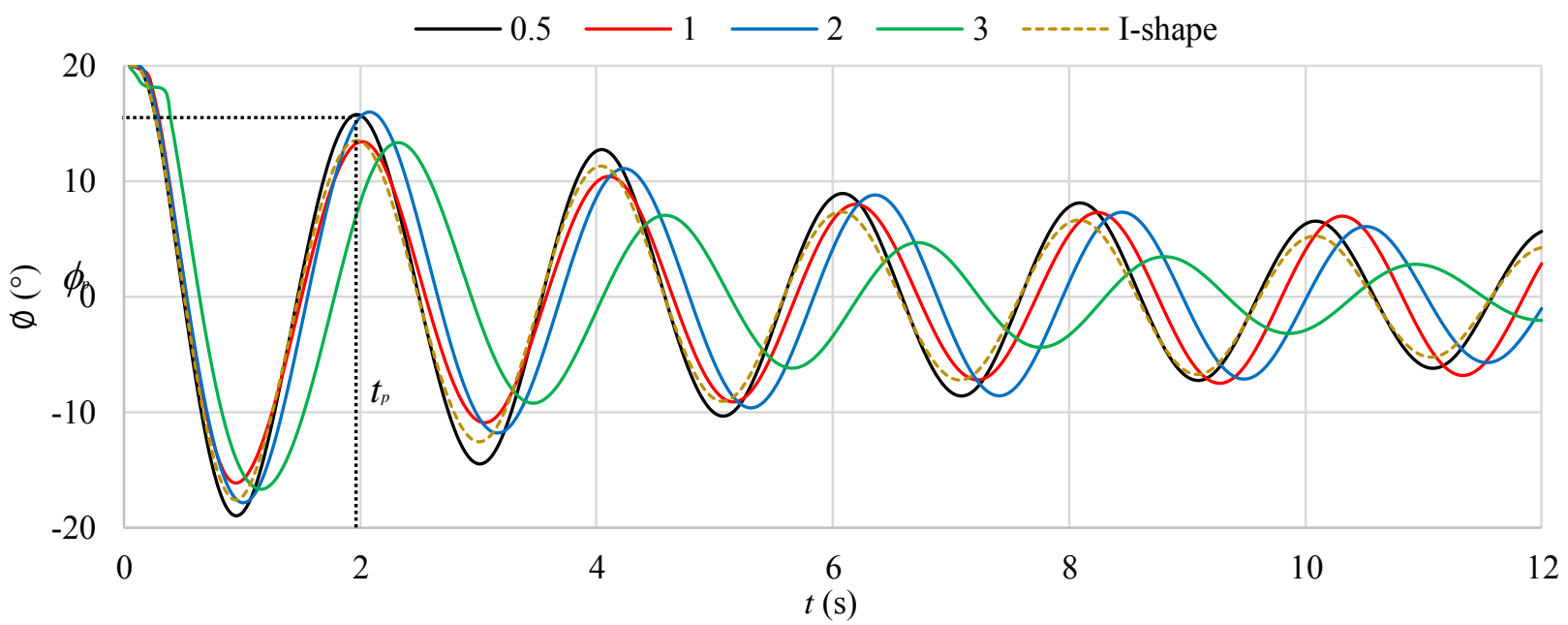

Figure 2 Roll angle history for boat with I-shaped bilge keels or T-shaped of different aspect ratio 
Each simulation is performed up to a period of 20 secs, but the analysis focusses on the first five cycles where damping is essential.

\section{Result \& discussion}

\subsection{Period and peak angle}

Figure 2 shows the roll angle history of the boat with Tshaped bilge keels of aspect ratios ranged from 0.5 to 3 , for a period of $12 \mathrm{~s}$. All designs exhibit similar sine wave profile with a decaying amplitude over the oscillations. The key differences are the rate of the decay of the roll amplitude and also the timing of the cycle's peak angle $t_{P}$. It is clear from the figure that the lowest aspect ratio $A R=$ 0.5 shows the largest amplitude in almost every cycle, which implies it has the lowest decrease of the amplitude. On the other hand, the largest aspect ratio $A R=3$ exhibits the lowest amplitude and hence shows the greatest decrease amplitude, over the oscillations. For $A R=1$ and 2 , there is no significant decrease of the amplitude. As for the timing of the peak angle $t_{p}, A R=0.5$ shows the earliest time, whereas $A R=3$ clearly shows the latest, indicating the cycle period is increased for larger aspect ratio. For the aspect ratio of 2 and 3, the period also increases over the cycles. It can be concluded that increasing the aspect ratio increases the damping of the rate of rolling but only increases the magnitude of the roll damping when the aspect ratio is increased to 3 .

Also shown on Figure 2 is the roll angle history of the boat with I-shaped bilge keels. The profile is quite similar with the $A R=0.5$, i.e. same timing of the peak angle $t_{p}$ but slightly lower amplitude. As a summary, the peak roll angle $\phi_{p}$ from Fig. 2 is replotted in Fig. 3, with a further addition of two interval aspect ratios $A R=1.5$ and 2.5. All cases show a $4^{\text {th }}$ order polynomial decrease. However, we also can clearly observe multiple crosses between the curves, indicating a non-linear relationship between the roll angle and the aspect ratio.

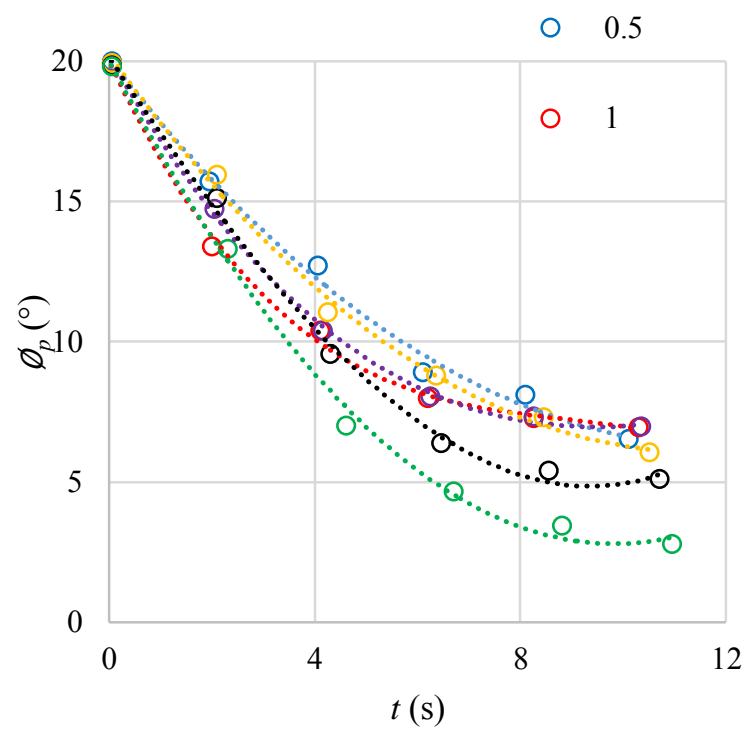

Figure 3. Peak roll angle $\phi_{p}$ as a function of $t$ for different aspect ratio $A R$.
The effect of changing the aspect ratio on the can be further quantified by considering the increment of the period $t_{a}$ over the cycles, with respect to the period for case $A R=0.5$, as shown in Fig. 4. Increasing the $A R$ almost always increases the period of the cycle, and the trend is an exponential increase with an increasing power for the later cycles. For example, at the first cycle, the aspect ratio $A R=3$ increases the period by $18 \%$ compared to only $8 \%$ and $2 \%$ for $A R=2$ and 1 , respectively. But at the fifth cycle, the period is significantly increased by $42 \%$ compared to $20 \%$ and $10 \%$ for $A R=2$ and 1 , respectively.

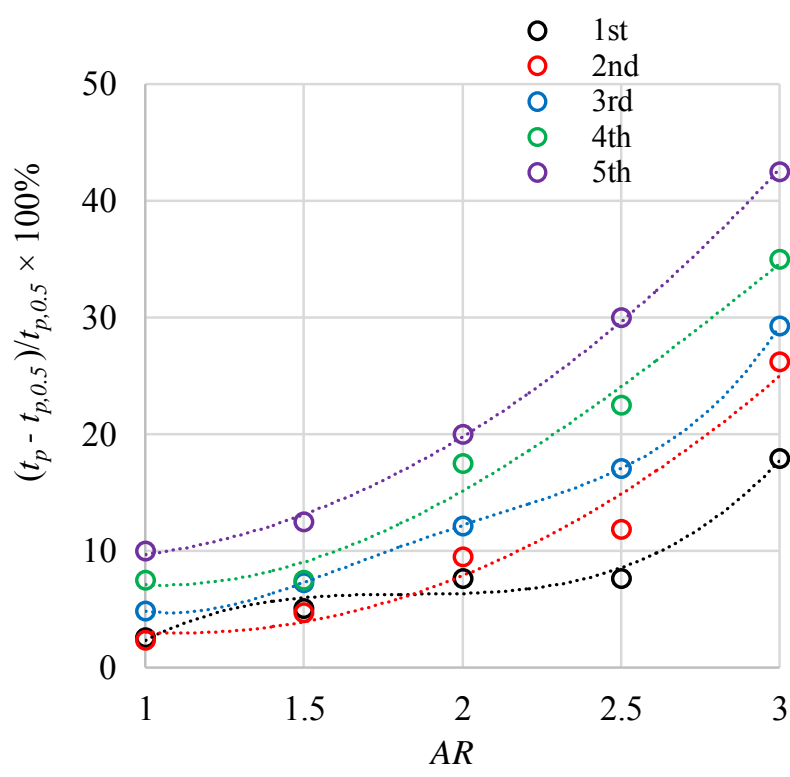

Figure 4. The percentage of period increment as a function of $A R$ for the first five cycles, with respect to the period of case $A R$ $=0.5, t_{p, 0.5}$.

The effect of the aspect ratio on the peak angle $\phi_{p}$ was

○ 1 st

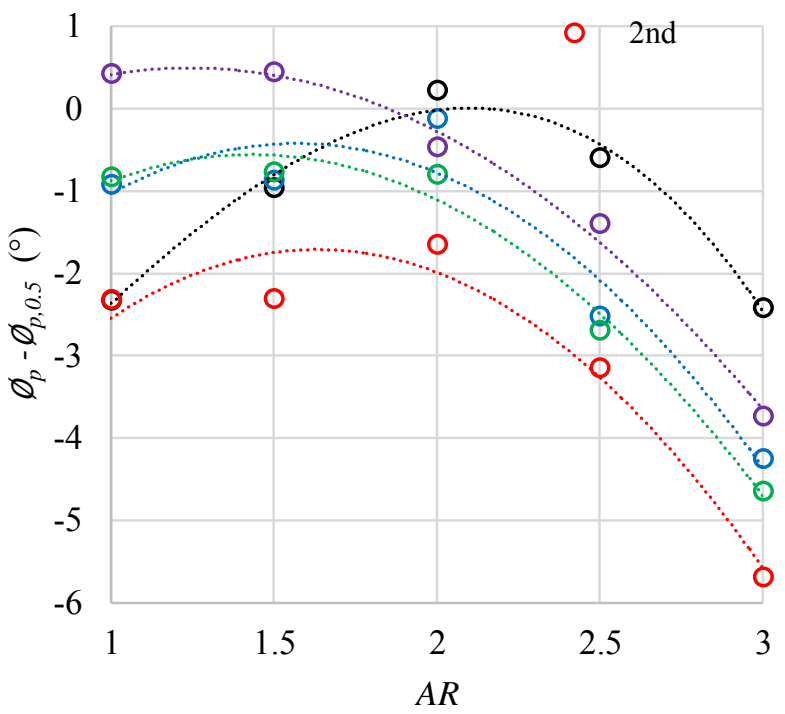

Figure 5. The change of peak roll angle $\phi_{p}$ with respect to the peak roll angle of case $A R=0.5, \varnothing_{p, 0.5}$, as a function of $A R$ for the first five cycles 
also further analysed. The change of the peak angle $\phi_{p}$ with respect to the peak angle of case $A R=0.5$ is shown in Fig. 5. It can be seen that increasing the aspect ratio of the bilge keels influences the amplitude non-linearly. The first cycle exhibits a quadratic curve but it gradually transitions into an exponential decrease at the fifth cycle. For the first four cycles, the amplitude increases with the increase of $A R$ and only decreases when $A R$ is increased beyond 2. Only in the last cycle, the roll angle always decreases for any increase of $A R$. It can be concluded that aspect ratio greater than 2 is necessary for an effective decrease on the roll angle. The maximum decrease of the roll angle varies from cycle to cycle. The peak angle is reduced by a maximum of only 2 degrees in the first cycle. It is 6 degrees in the second cycle, and between 2 and 6 degrees for the third to fifth cycles.

\subsection{Damping coefficient}

It is customary to describe a free roll decay motion using a linear equation of motion

$$
(I+A) \ddot{\emptyset}+B_{l} \dot{\varnothing}+C \varnothing=0
$$

where $(I+A)$ is the roll moment of inertia, $B_{l}$ is the damping coefficient and $C$ is the stiffness coefficient. The linear damping coefficient is given by

$$
B_{l}=2(I+A) \zeta \omega_{n}
$$

The damping ratio $\xi$ and natural frequency $\omega_{n}$ are defined as

$$
\begin{gathered}
\xi=\frac{1}{\sqrt{1+\left(\frac{2 \pi}{\delta}\right)^{2}}} \\
\omega_{n}=\frac{2 \pi}{T_{n}}
\end{gathered}
$$

where $\delta$ is the logarithmic decrement of two successive peaks. Based on the first six successive peaks, the linear damping coefficient is then computed using equations (2) to (4). The result is shown in Figure 6. It can be seen that the behavior is a quadratic trend. The damping initially decreases and then increases when $A R$ is greater than 1.5. This again shows a nonlinear effect of the bilge keel size on the roll moment and pressure around the hull, in agreement with Irkal et al. [2] observation.

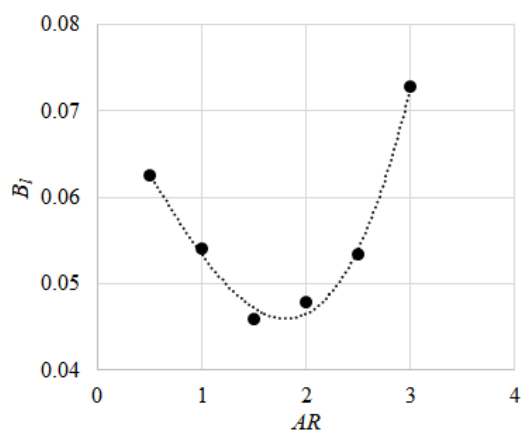

Figure 6. $B_{l}$ as a function of $A R$.

\subsection{Eddies and vortices}

The underlying physics that leads to the increase of the damping is the influence of the bilge keels on the flow surrounding the boat. The keels obstruct the flow close to the boat and generates vortices that increases the pressure and the shear force on the boat. This mechanism is shown on Figure 5 for the I-shaped, and T-shaped keel of aspect ratio $A R=1$ and 3. However, it can be seen that $\mathrm{T}$-shaped keel is able to generate significantly greater vorticity and eddies at the tip of the bilge keel, a maximum value of $200 \mathrm{~s}^{-1}$, which is four times greater than that of either Ishaped keel or T-shaped of $A R=1$. The large vorticity increases the pressure being applied at the tip of bilge keel. This highlights the advantage of increasing the surface area of the bilge keel. However, $A R$ greater than 2 is necessary in order to achieve vortices generation that is significantly greater than that of I-shaped keel bilge.
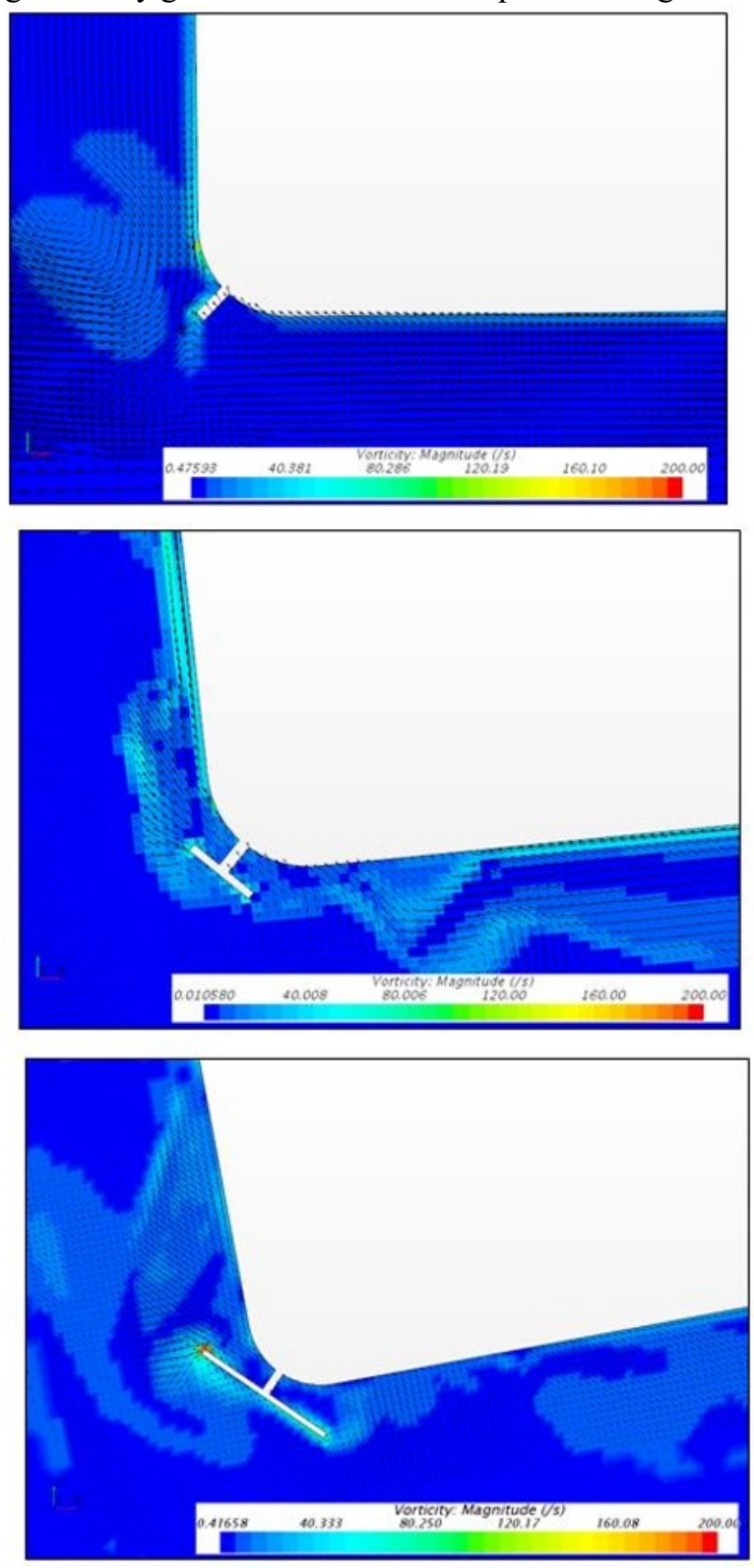

Figure 7. Vorticity magnitude and velocity vector contour of (top) I-shaped, (middle) T-shaped with $A R=1$, (bottom) T-shaped with $A R=3$, at time $t=2.4 \mathrm{~s}$. 


\section{Conclusions}

This work presents a numerical study on the effect of Tshaped bilge keels on the roll damping of a conventional boat. The analysis focusses on the effect of the aspect ratio of the T-shaped bilge keels on the peak roll angle and the period of the oscillations. The following conclusions are drawn:

1. Increasing the bilge keel aspect ratio influences the damping coefficient non-linearly. Due to this effect, the peak roll angle also changes non-linearly. As a result, sufficiently large aspect ratio, i.e. aspect ratio greater than 2 , is necessary in order to obtain an effective decrease of the peak angle.

2. The damping on the period of the cycle, on the other hand, increases consistently and exponentially with an increasing aspect ratio. The effect is greatly increased at later cycle.

3. The non-linear damping is attributed to the non-linear increase of the eddies and vortices generation at the tip of the keel.

\section{References}

1. R.A. Ibrahim, I.M. Grace. Modeling of ship roll dynamics and its coupling with heave and pitch. Mathematical Problems in Engineering, 2010.

2. M.A. Irkal, , S. Nallayarasu, S.K. Bhattacharyya. CFD approach to roll damping of ship with bilge keel with experimental validation. Applied Ocean Research, 55, pp.1-17. 2016.

3. E.P. Bangun, EP, C.M. Wang, T. Utsunomiya. Hydrodynamic Forces on a Rolling Barge with Bilge Keels." Applied Ocean Research, 32(2), 219-232. 2010

4. Y. Ikeda. Prediction methods of roll damping of ships and their application to determine optimum stabilization devices. Marine Technology, 41(2), pp.89-93. 2004
5. K.P. Thiagarajan, E.C. Braddock. Influence of Bilge Keel Width on the Roll Damping of Fpso. Journal of Offshore Mechanics and Arctic Engineering, 132(1), 011303. 2010

6. F. Jaouen, A. Koop, G. Vaz. Predicting roll added mass and damping of a ship hull section using CFD. In ASME 30th International Conference on Ocean, Offshore and Arctic Engineering, pp. 105-115. 2011

7. R. van't Veer, X.B. Schut, R.H.M. Huijsmans. Bilge Keel Loads and Hull Pressures Created by Bilge Keels Fitted to a Rotating Cylinder. Applied Ocean Research ,53, 1-14. 2015

8. S.A. Kinnas, Y.H. Yu, V. Vinayan. Numerical methods for the prediction of the bilge keel effects on the response of ship-shaped hulls. In ASME 26th International Conference on Offshore Mechanics and Arctic Engineering, pp. 1023-1030. 2007

9. Y.J. Kim, I.K. Kang, B.S. Park, S.J. Ham. An optimal bilge keel design to reduce the rolling of the offshore large purse seiner. Journal of the Korean society of Fisheries Technology, 50(2), pp.147-153. 2014

10. B. Ommani, T. Kristiansen, O.M. Faltinsen, Simplified CFD modeling for bilge keel force and hull pressure distribution on a rotating cylinder. Applied Ocean Research, 58, pp.253-265. 2016

11. G.O.G. Avalos, J.B. Wanderley. Numerical study of forced roll oscillation of FPSO with bilge keel. Ocean Engineering, 147, pp.304-317. 2018

12. K.G. Aarsæther, D. Kristiansen, B. Su and C, Lugni. Modelling of Roll Damping Effects for a Fishing Vessel with Forward Speed. In ASME 34th International Conference on Ocean, Offshore and Arctic Engineering . 2015 